\title{
FENOMENOLOGIA HERMENÊUTICA DA EXPERIÊNCIA MÍSTICA SEGUNDO MARTIN HeIDEgGER
}

\author{
[HERMENEUTIC PHENOMENOLOGY OF MYSTICAL EXPERIENCE ACCORDING TO MARTIN \\ HEIDEGGER]
}

RESUMo: O presente artigo tem por objetivo dar a compreender a mística cristã como uma experiência de transcendência na imanência. Para tanto, toma como ponto de partida a análise fenomenológica hermenêutica da mística medieval esboçada por Heidegger em seu curso não ministrado de verão de 1918/19, intitulado Fundamentos Filosóficos da Mística Medieval. Apesar de não ter sido completado, o curso fornece indicações importantes a respeito do modo como seria possível desenvolver uma fenomenologia hermenêutica da mística medieval, e sugere a descrição da experiência mística feita por Santa Teresa de Ávila como paradigma de uma visão fenomenológica da mística. Este artigo procura, portanto, seguir tais indicações, no intuito de apresentar em que consiste a fenomenologia da mística cristã à luz das indicações de Heidegger e da interpretação dos textos de Santa Teresa de Ávila.

Palavras-chave: Fenomenologia; Mística; Espiritualidade; Heidegger; Teresa de Ávila
ABSTRACT: This article aims to describe a phenomenological interpretation of Christian Mystic as an experience of transcendence in immanence. As basis to this description, it was taken the hermeneutical and phenomenological analysis made by Heidegger at his lectures prepared to summer semester 1918/1919, published with the title Philosophical Grounds of Middle Age Mystic. At this text, he suggests that the mystical experience described by Theresia of Ávila in her books could be taken as a paradigmatical phenomenological vision of mystic. This article follows this indication, and it searches to presents in what sense Heidegger says that the description of Theresia of Ávila must be taken as a basis to develop a phenomenological hermeneutical vision of Christian Mystic.

KEYWORDS: Phenomenology; Spirituality; Mystic; Heidegger; Theresia of Ávila

em sempre se tem em conta que a experiência espiritual constitutiva da vida
religiosa mantém uma conexão fundamental com a filosofia e a arte, além da ciência da religião ou da teologia, como já comumente se espera. Nem mesmo se pensa a experiência espiritual como objeto digno de ser estudado pela filosofia. Tem-se em geral a impressão de que a espiritualidade é coisa para teólogos e místicos, não para filósofos. A verdade, porém, é que muitos filósofos tiveram a preocupação de se ater à experiência religiosa e à espiritualidade que nela se constitui, especialmente com vistas à compreensão de uma filosofia da religião.

E como aqui procura-se pensar como poder-se-ia constituir uma fenomenologia da vida religiosa e em que ela consiste, convém que se reporte, para começo de

* Professor Adjunto do Departamento de Filosofia da Universidade Federal da Paraiba. E-mail: gilfranco.lucena@academico.ufpb.br 
conversa, a um fato curioso, que foi legado por uma carta de Edith Stein escrita a seu amigo e colega no Círculo Fenomenológico de Göttingen, Roman Ingarden, a respeito de um encontro e uma conversa entre ela, Husserl e Heidegger sobre filosofia da religião. Edith Stein estava em Freiburg, onde era assistente de Husserl, e escreve a carta para Ingarden no dia 08 de junho de 1918. Ali ela escreve: "Caro Senhor Ingarden, hoje o senhor não teve sorte. Eu fui até Husserl hoje ao anoitecer, pra tratar com ele a respeito de seu trabalho, mas acabei encontrando na ocasião o pequeno Heidegger, e nós acabamos fazendo um passeio a três - a propósito maravilhoso conversando sobre filosofia da religião, que se desenvolveu até mais de meia noite" (ESGA 4, p. 85). Que Stein, Heidegger e Husserl tenham conversado nessa noite do ano de 1918, poucos meses antes dos quais Heidegger teria preparado sua preleção de inverno de 1918/19 sobre Os fundamentos filosóficos da mística medieval, é, no mínimo, um fato curioso e digno de nota. Apesar de Edith Stein só vir a se preocupar com a elaboração de uma filosofia da religião um pouco mais $\operatorname{tarde}^{1}$, ainda que ao mesmo tempo em que Heidegger se via às voltas com esse assunto em seus cursos, o tom com o qual Edith Stein fala da conversa, sua duração e o modo como ela a julga, diz muito da importância do tema para aqueles filósofos naquele instante. $\mathrm{O}$ que teriam conversado e como a conversa se desenrolou ou em torno de que problemas, não sabemos dizer com exatidão. Certamente dizia respeito ao modo como a fenomenologia haveria de abordar a experiência religiosa e o problema de Deus.

No projeto dessa sua preleção, preparada para o semestre de inverno de 1918/19, que não foi proferida, Heidegger nos legou uma primeira ideia importante da conexão entre filosofia e mística, ao procurar falar, em perspectiva fenomenológica e hermenêutica, dos fundamentos filosóficos da mística medieval. É esta ideia que se procurará apresentar aqui, com base nos esboços expostos por Heidegger e, seguindo suas indicações, tentar-se-á desenvolver uma fenomenologia hermenêutica da mística a partir dos textos de Teresa de Jesus.

\section{A Ideia de uma Fenomenologia Hermenêutica da Mística Medieval}

Heidegger nos dá a compreender a mística - aquela medieval em particular como "forma de expressão da vivência religiosa" (GA 60, p. 306). De acordo com Heidegger, uma fenomenologia da vida religiosa, que pretenda fornecer os fundamentos filosóficos, há de apresentar tais fundamentos como: "meio da formação da expressão; meio dos caminhos da própria vivência; meio da sistemática (expressão 'conceitual')" (GA 60, p. 306). Trata-se, segundo ele, de "apanhar os momentos de constituição da vivência mística" e "particularmente o fenômeno do amor de Deus" (GA 60, p. 306). $\mathrm{Na}$ investigação, há de se distinguir "a vivência pura como tal, a expressão (os elementos expressivos), o esclarecimento (significado), o uso" (GA 60, 307).

De acordo com Heidegger: "As formas de vivência são sempre só e somente passíveis de serem extraídas a partir das suas situações genuinamente possíveis e círculos de situações na essência", isto é, "trata-se justamente dos sentimentos concretos no eidos" (GA 60, p. 307). Trata-se, portanto, de extrair as formas e expressão da vivência mística da concretude eidética de seus círculos de situação. O tempo é aí entendido não linearmente, mas "como motivo".

Heidegger se pergunta: "Como se exprime uma vivência religiosa?" (GA 60, p. 305). De acordo com ele, é a oração que se impõe como expressão da vivência religiosa: “'Oração' como Expressão ['Gebet'als Ausdruck]” (GA 60, p. 305).

Para pensar a "constituição da objetividade religiosa", Heidegger coloca as 
seguintes perguntas: "Deus se constitui na oração? Ou ele está já previamente dado de algum modo religiosamente na fé ('amor')? E a oração [é] um modo de relacionar-se com ele?" (GA 60, p. 307).

A partir dessas questões, Heidegger estabelece o ponto de partida para uma fenomenologia eidética da mística como forma de expressão da vida religiosa, que aqui deve ser também distinta da mera devoção. Tal fenomenologia eidética deve ser também "hermenêutica", na medida em que "trabalha no eu histórico" (GA 60, p. 336) e, neste sentido, "a eidética intuitiva como hermenêutica nunca é teoreticamente neutra, mas tem mesmo só eideticamente [...] a agitação do mundo da vida genuíno" (GA 60, p. 336) ${ }^{3}$. De acordo com Heidegger, o problema exige a conquista e compreensão de tais fenômenos, originalmente visados na consciência pura e sua constituição, "a partir do histórico" e de "sua facticidade na compreensão original fenomenológica" (GA 60, p. 303). E aqui se situa a "dificuldade: somente um homem religioso pode compreender a vida religiosa, pois de outro modo ele não teria qualquer acesso genuíno a essa região fenomenal" (GA 60, p. 304). A mística medieval se oferece aqui como horizonte histórico no interior do qual o passado se abre numa possibilidade decisiva.

Como a publicação não foi desenvolvida, e temos dela, por assim dizer, apenas um esboço, nosso objetivo é fundamentalmente retomar o horizonte desse método aqui exposto e, numa retomada das questões decisivas aqui em jogo, procurar compreender a experiência mística enquanto experiência espiritual como tal, em diálogo com um de seus paradigmas fundamentais. ${ }^{4}$

Porém, como se trata de entender aqui a espiritualidade na experiência mística, e sua conexão com a filosofia e a arte, nosso objetivo está em compreender como se caracteriza, na experiência mística a visão espiritual (ou "visão de Deus" ["Schauen Gottes"], tal como Heidegger nomeia em um momento da preleção; cf. GA 60, p. 308). Faz-se necessário investigar e entender a visão de Deus como visão espiritual, à luz de uma fenomenologia da mística como forma de expressão da vivência religiosa, levando em conta, primeiramente, as questões levantadas por Heidegger.

Como interlocutora, toma-se aqui outra indicação dada por Heidegger. Trata-se do pensamento da mística carmelita Teresa de Jesus, que se dedicou a dar a compreender a experiência de Deus através da oração. Ora, como o próprio Heidegger assegura, "St." Teresa vê como mística fenomenologicamente", ainda que não eideticamente nem na perspectiva da elaboração de uma "eidética especificamente religiosa" (GA 60, p. 336). Assim, tomaremos para a nossa interpretação os momentos constitutivos da experiência de oração tal como Santa Teresa os evoca, no intuito de, por um lado, caracterizar sua "estrutura" eidética e, por outro lado, compreendendo o seu modo, por assim dizer, artístico de expressão. Desse modo, podemos cumprir a tarefa de explicitar eideticamente o caráter filosófico e artístico (ou estético) da espiritualidade (ou experiência espiritual). Tentaremos tornar nítido, que a experiência espiritual em geral e o "olhar espiritual"s ou "visão intelectual"" em particular pode ser ontologicamente compreendida como uma experiência de transcendência na imanência. Isto significa onticamente que, na experiência espiritual religiosa, tudo se constitui na imanência da consciência religiosa (determinada fundamentalmente pela pistis que a origina, pela noética transcendental que a pensa, e pela eikasía artística e simbólica que a exprime). Tal experiência aponta e orienta a alma para "aquilo"7, que de algum modo é fundamento desta experiência, ou a fonte de sua essência e, de algum modo, ao mesmo tempo, a ultrapassa. "Aquele" em direção a quem a alma se mantém orientada na experiência religiosa como fonte de sua essência, não "está", por assim dizer "na" consciência, mas "a ela se comunica". Essa consideração de Deus, do mistério ou da graça como fonte da essência é o que constitui a "objetualidade" da experiência como 
esse transcendens (ser transcendente). Na consciência fenomenológica que se volta para a consciência religiosa em respeito ao fenômeno que aí se constitui e sua expressão, Deus e seu ato (mistério e graça) só podem ser pensados como esse transcendens, em comunicação com a consciência, em cuja imanência, a ele se atém, e se relaciona com aquilo que compreende como sua manifestação correspondente.

Sob esse aspecto poder-se-á concluir que: a única coisa que a consciência em orientação fenomenológica pode dizer de Deus e sua ação é que são esse transcendens, sem mais nada precisar nem poder supor. Pois é disso que a consciência religiosa dá testemunho em sua vivência espiritual, no âmbito da fé. O trabalho de "configuração" desse ser transcendente pela consciência religiosa é um trabalho de composição estética à luz da vivência ou que exprime a vivência (de maneira alegórica ou analógica), e é, por assim dizer, propriamente artístico ${ }^{8}$. É por isso que, como pretende descrever a experiência de fé, a expressão da experiência espiritual da vida religiosa é muito mais artística que filosófica, sem poder confundir a imagem expressa com a realidade do mistério. Caso se comportasse dessa maneira, tornar-se-ia idólatra, e, neste sentido, a consciência religiosa enganar-se-ia, isto é, tornar-se-ia vítima de um autoengano.

Se, pois, a vivência religiosa tem a oração como sua expressão, para responder à questão sobre como Deus se constitui na oração de modo já previamente dado religiosamente na fé (no amor), e como a oração se constitui em um modo como relacionar-se com ele, tomaremos, como solo para a reflexão, os graus através dos quais Santa Teresa de Jesus estabelece o caminho orante da consciência religiosa.

\section{A Experiência Espiritual de Santa Teresa de Jesus como Paradigma}

Ao indicar Santa Teresa como exemplo de uma mística que vê fenomenologicamente, Heidegger toma o Castelo Interior $(C I)$ como base para sua investigação. Na caracterização simbólica (alegórica) da alma como um Castelo no qual Deus habita, "a morada de Deus", Heidegger vê a "motivação original (Urmotivation)", que indica "o fenômeno do recolhimento (interior) e suas motivações e tendências" (GA 60, p. 336), cujos fenômenos particulares que o constituem são "a quietude mística, o silêncio, o problema do acesso ao eu" (GA 60, p. 336), "as tendências fundamentais da vida", que implicam em um "mais-viver", a partir do qual se constitui "a atividade meditativa motivada de sentido" (GA 60, p. 336). Estas "efetividades da vivência do religioso devem emergir e crescer a partir de si", e o religioso "deve deixar operar em si as conexões imanentes" (GA 60, p. 335-336), que, por sua vez, indicam o "fenômeno do processo de constituição da presença de Deus" como um fenômeno "originário” (GA 60, p. 336).

Ao citar Santa Teresa, Heidegger enfatiza o caráter irrenunciável da experiência como tal, em que a compreensão da alma como morada de Deus, enquanto motivação original, deve primeiro que tudo ser apreciada como digna de valor. E cita o que Santa Teresa de Jesus ressalta: “... sabemos que tenemos alma; mas qué bienes puede haver em esta alma u quién está dentro em esta alma u el gran valor de ella,

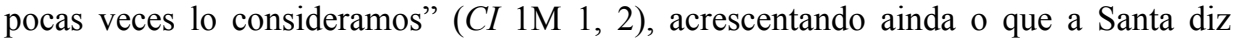
sobre a fé e a experiência e sua importância para a compreensão do fenômeno: “... quien esto [como o fato de Deus morar na alma - o religioso e santo em geral] ${ }^{9}$ no

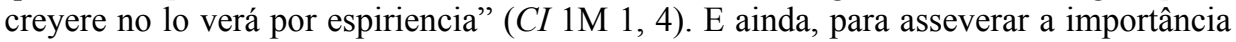
da experiência, acrescenta: "porque es bien dificultoso lo que queria daros a entender, si no hay experiencia" (CI 1M 1,9). E, nesta experiência, o que se enseja, acrescenta Heidegger, é "ver sempre o mais interior e total do castelo", não simplesmente de 
maneira superficial ou parcial, mas "visão total e compreensiva” (GA 60, p. 337).

Ora, justamente Santa Teresa assegura, que este caminho para o interior se constitui passo a passo pela oração, pela qual, segundo Heidegger, o fenômeno do processo de constituição da presença de Deus se caracteriza como um fenômeno originário. Diz Teresa: “... la puerta para entrar en este castillo es la oración y consideración; no digo más mental que vocal, que como sea oración ha de ser con consideración" (CI 1M 1,7). E o objetivo é, como Heidegger bem julgou, chegar a uma visão total e compreensiva: compreender o que é a alma, e ver quem nela habita em seu mais profundo centro. Pois, como Santa Teresa haverá de dizer na Sétima Morada do Castelo Interior: "Quiere ya nuestro buen Dios quitarla las escamas de los ojos y que vea y entienda algo de la merced que le hace" $(C I 7 \mathrm{M} \mathrm{1,6).}$

De acordo com Santa Teresa de Jesus, "este centro de nuestra alma - u este espíritu - es una cosa tan dificultosa de decir" (CI 7M 2, 14). Mas a visão constituída neste centro mais profundo da alma, "en lo muy muy interior" (CI 7M 1,8), é denominada pela Santa de "visión intelectual" (CI 7M 1,7); pois, acrescenta a Santa: "hay diferencia en alguna manera, y muy conocida, del alma a el espíritu, aunque más sea todo uno" (CI 7M 1, 12), de modo que: "Aparécese el Señor en este centro del Alma sin visión imaginaria, sino intelectual" (CI 7M 2, 3). Em que consiste esta visão intelectual, na qual finalmente se estriba a espiritualidade? Para chegar a caracterizá-la minimamente, faz-se necessário acompanhar como Santa Teresa indica os passos do caminho para o interior do castelo e em que ele consiste.

Já no Castelo Interior $(C I)$ poderíamos caracterizar bem esse caminho e em que ele consiste. Mas neste primeiro momento, tomaremos este livro apenas para caracterizar o ponto de partida e o ponto de chegada, dado que compreender o caminho tal como se apresenta neste livro, exigiria de nós mais tempo, dado sua amplitude. Por isso, para fazer a apresentação geral dos passos do caminho, tomaremos como base para a interpretação o livro da Vida ( $V$ ) de Santa Teresa, no qual, diferentemente do Castelo Interior $(C I)$, Santa Teresa se utiliza da metáfora da plantação e irrigação de um jardim, para mostrar alegoricamente em que consistem os graus de oração que conduzem a alma a uma união espiritual com Deus.

\section{O Ponto de Partida do Caminho à luz da alegoria do Castelo Interior (CI)}

À luz da metáfora da alma como um castelo, o texto bíblico que a santa toma como base é Ap 21,10-23. Semelhante a esse texto, no primeiro capítulo do Castelo Interior, a alma é vislumbrada "como um castelo todo de um diamante ou cristal muito claro, onde há muitos aposentos, assim como no céu há muitas moradas" (CI 1M 1,1). E aqui ela estabelece a conexão com o que já havia dito no livro da Vida, isto é, a metáfora do jardim, pois, diz ela: “... não é outra coisa a alma do justo senão um paraíso onde Ele [o Senhor] diz ter seus deleites" (CI 1M 1,1; cf. Provérbios 8,31). A formosura da alma é compreendida à luz da ideia estabelecida em Gn 1,26, segundo a qual a alma foi criada por Deus à sua imagem e semelhança. Pois assevera a Santa:

si esto es, como lo es, no hay para qué nos cansar en querer comprehender la hermosura de este castillo; porque puesto que hay la diferencia de él a Dios que del Criador a la criatura, pues es criatura, basta decir su Majestad que es hecha a su imagen para que apenas podamos entender la gran dignidad y hermosura del ánima. (CI 1M 1,1).

Por isso, Santa Teresa ressalta que: "No es pequeña lástima y confusión que 
por nuestra culpa no entendamos a nosotros mesmos ni sepamos quien somos" $(C I 1 \mathrm{M}$ $1,2)$, de tal modo que "ansí se tiene en tan poco procurar con todo cuidado conservar su hermosura" (CI 1M 1,2). Ora, de fato, como se pode buscar os meios para conservar a formosura da alma se não sabemos os bens que nela existem, quem nela reside e o grande valor que ela tem?

Daqui emerge o conhecimento de si como tarefa, que Heidegger considerou como traço de um caminho para o eu: "das Problem des Ich-Bezugs", isto é, o problema do acesso ao eu (cf. GA 60, p. 336). O conhecimento de si emerge como tarefa para que a alma não viva na ignorância a respeito de si mesma, de modo a permanecer apenas, como diz a santa, "en la grosería del engaste u cerca de este castillo, que son estos corpos" (CI 1M 1,2). Assim, a Santa nos convida a considerar como ponto de partida e de maneira simbólica (metafórica), nossa alma como um castelo que tem "muchas moradas, unas en lo alto, otras en bajo, otras a los lados, y en el centro y mitad de todas estas tiene la más principal, que es adonde pasan las cosas de mucho secreto entre Dios y el alma" (CI 1M 1,3). E a pergunta fundamental deste ponto de partida é agora: "como podemos entrar en él?" (CI 1M 1,5).

Mas não parece um desatino, pergunta-se Santa Teresa, entrar no que de algum modo já se é? Diz ela: "Parece que digo algún disbarate; porque si este castillo es el ánima, claro está que no hay para qué entrar, pues se es él mesmo; como parecía desatino decir a uno que estrase en una pieza estando ya dentro" (CI 1M 1,5). Para sair desse paradoxo, Santa Teresa considera que há diversos modos de estar. Diz ela:

... havéis de entender que va mucho de estar a estar; que hay muchas almas que se están en la ronda del castillo - que es adonde están los que le guardan - y que no se les da nada de entrar dentro ni saben qué hay en aquel tan precioso lugar ni quién está dentro ni aún qué piezas tienen. (CI $1 \mathrm{M} 1,5)$

E a santa conclui dizendo que, isto que ela pensa, é igual ao que ouviu em alguns livros de oração, que recomendam à "alma que entre dentro de sí" (CI 1M 1,5)

Santa Teresa considera, então, que "la puerta para entrar en este castillo es la oración y consideración" (CI 1M 1,7), aquilo que, como sugeriu Heidegger, se constitui como expressão da vivência religiosa (oração como expressão, Gebet als ausdruck), e possível meio ou horizonte intencional no interior do qual Deus se constitui pela fé (cf. Heidegger, 1995, p. 305). De um ponto de vista formal, para Heidegger, a oração é: 1) expressão da vivência religiosa; 2) horizonte no qual possivelmente alguém como Deus se constitui; ou 3) estando Deus "previamente dado de algum modo religiosamente" na fé ( $\pi i \sigma \tau \iota \varsigma)$ a oração exprime a relação com ele. Mas, o que são, na exposição de Santa Teresa a oração e consideração, apresentadas metaforicamente como porta de estrada do castelo?

Aqui introduz-se o "mistério" da atenção à palavra pronunciada mental ou vocalmente, isto é, o "mistério" ou "atividade" ou "exercício" da meditação ${ }^{10}$. E aqui, dando atenção às formas da vivência religiosa da mística medieval, através de uma de suas representantes fundamentais, tem-se a possibilidade de ter acesso ao seu fundamento filosófico, isto é, ao meio de formação da expressão ${ }^{11}$, do caminho da própria vivência e da sistematização de sua expressão conceitual. Aquilo que aqui vemos em Santa Teresa e sua expressão é o que Heidegger caracterizou como um "fenômeno do processo de constituição da presença de Deus", como um fenômeno "originário", e que se constitui através dos seguintes "passos da oração": "concentração, meditação, oração de quietude" (Heidegger, 1995, p. 336).

Ao falar que "a porta para entrar neste castelo é a oração e consideração", ela acrescenta que, com isso, não pretende dizer que se trata de oração "mais mental que 
vocal", uma vez que, tratando-se de oração, esta "há de ser com consideração" (CI 1M 1,7). Esta advertência revela dois aspectos fundamentais: 1) primeiro que, ao falar de oração, Teresa não pensa simplesmente em um mero processo de reflexão ou concentração numa interioridade vazia; trata-se antes do estabelecimento de uma relação com uma palavra transmitida, que diz algo e que, portanto, há de ser vocalizada, isto é, trazida à fala na voz de quem reza, já que pretende entrar pela porta da oração. A meditação orante mostra-se, portanto, já de início, uma relação com alguma coisa que foi dita, e que quem ora traz à fala na meditação, dizendo de novo para si mesmo o que foi dito. 2) Por outro lado, em segundo lugar, outro aspecto fundamental é que a oração vocal não consiste simplesmente em repetir vocalmente as palavras transmitidas, mas é preciso repetir com consideração, isto é, com atenção e concentração na palavra meditada vocalmente. A oração e consideração, portanto vocal e mental da oração, assume, desse modo, um caráter duplo: tem a ver por um lado com a repetição de uma palavra transmitida vocalmente e que há de se tornar patente de novo vocalmente na boca de quem reza, pelo som de sua voz (aspecto "objetivo" da oração e que está relacionado com a revelação transmitida historicamente); por outro lado, o dito vocalmente e agora repetido requer uma atitude específica de quem reza, que há de ter em conta atentamente o significado do que se diz na oração (aspecto "subjetivo" da oração e que está relacionado com o modo como o crente se relaciona com a verdade revelada, a ele transmitida).

Desse modo, na oração vocal e mental não há somente repetição vocal das palavras, mas fundamentalmente uma repetição kairológico-histórica da atitude que tais palavras requerem de quem reza. Porque, diz Santa Teresa, "a que não tem em conta com quem fala e o que pede e quem é que pede e a quem, eu não a chamo oração, mesmo que se mexam muito os lábios" $(C I 1 \mathrm{M} 1,7)^{12}$. O que seria, então, para Santa Teresa, aquilo que ela verdadeiramente chamaria de oração? Para responder a essa questão, é necessário levar em conta as seguintes questões: 1) Como ela considera quem é aquele que fala? 2) Como ela considera o pedido, isto é, o que pede? 3) Quem pede e a quem pede? Para responder a estas perguntas, é preciso que se requisite outro livro de Santa Tereza, intitulado Caminho de Perfeição $(C P)$, não somente porque é lá que ela caracteriza o que é a oração mental e vocal, mas fundamentalmente porque é lá que ela pode ajudar a responder as perguntas levantadas, pelas quais podemos entender precisamente o que é a oração vocal e mental.

\section{O CAMinho de PERfeiÇÃo (CP) À LUZ da Alegoria do "JaRdim" no LiVRo DA $\operatorname{VIDA}(\boldsymbol{V})$}

De acordo com Santa Teresa, se a porta de entrada para o Castelo da Alma é a oração com consideração, isto quer dizer que a oração vocal com que se começa a oração não deve estar separada da oração mental, pois na oração, a mente deve estar concentrada no que a boca diz e pronuncia. Pois, diz a Santa: "si hablando estoy [e rezando vocalmente] [y] enteramente entendiendo y viendo que hablo con Dios y tengo advertencia en las palabras que digo, junto está oración mental con vocal" ( $C P$, Codice de Valladollid, cap. 22,1; Codice de El Escorial, cap. 37,133). Já de acordo com o que ela escreveu no livro da Vida, este é o primeiro grau de oração para Santa Teresa: a oração vocal e mental. Neste grau, o trabalho consiste fundamentalmente no esforço pelo recolhimento dos sentidos e em um intenso trabalho das faculdades da alma (o intelecto, a memória e a vontade).

No livro da Vida Santa Teresa se utiliza de uma bela comparação (ou parábola) 
para nos dar a compreender em que consiste a oração em cada um de seus graus, pretendendo “... declarar algo de quatro grados de oración, en que el Señor, por su bondade, há puesto algunas veces mi alma" $(V 11,8)$. Diz ela:

ha de hacer cuenta el que comienza, que comienza a hacer un huerto en tierra muy infructuosa que lleva malas hiervas, para que se deleite el Señor. Su Majestad arranca las malas hiervas y ha de plantar las buenas. $(V 11,8)$

Deixa-se depreender destas palavras de Santa Teresa a respeito dos que começam a ter oração que a primazia não é do indivíduo que reza, mas de Deus, que toma a iniciativa de preparar a alma para o cotidiano encontro com ele. Desde o ponto de vista de uma fenomenologia eidética fundada na expressão, aqui se manifesta à consciência religiosa o senso de infusão de um dado reconhecido como transcendente, que se comunica na imanência da consciência ${ }^{14}$. A consciência de Deus como esse transcendens que se antecipa à experiência de oração. O terreno infértil é preparado por Deus, que, de acordo com Teresa, arranca as ervas más e há de plantar as boas através da oração. Esta oração, aqui, há de ser pensada como um testemunho herdado da revelação de Deus e enviado à existência histórica. É por isso que quando, no Caminho de Perfeição $(C P)$, Santa Teresa vai falar da oração vocal e mental, ela evoca a oração do Pai nosso como oração paradigmática. Este já estar preparado da alma que começa a ter oração, revela uma dimensão não só psíquica, mas também histórica. A história é a história da revelação; a história de uma comunicação de Deus com o ser humano e do ser humano com Deus, que passa fundamentalmente pelo mistério da revelação de Deus na pessoa de Jesus, por quem se constituiu essa comunicação. É dentro desse horizonte histórico que Teresa se situa; por isso a oração que Jesus ensinou aos discípulos ganha uma importância fundamental na compreensão de Teresa. Em geral passa-se despercebido por esse aspecto, em função do acento na questão das virtudes morais.

Assim, levando em conta que este terreno já está preparado para os que começam a ter oração, diz Santa Teresa:

hagamos cuenta que está ya hecho esto cuando se determina a tener oración un alma, $[. .$.$] ; y con ayuda de Dios hemos de procurar, como buenos hortelanos, que$ crezcan estas plantas y tener cuidado de regarlas para que no se pierdan, sino que vengan a echar flores que den de si gran olor, para dar recreación a este Señor nuestro, y ansí se venga a deleitar muchas veces a esta huerta y a holgar-se entre estas virtudes. ( $V 11,6)$

A oração é, assim, pensada por Santa Teresa como um cultivo. A alma é uma terra a ser cultivada; uma terra na qual Deus há de plantar um horto ou jardim (um Carmelo/ Karmur). A oração deve ser um cultivo das virtudes plantadas. Como a oração há de ajudar ou favorecer o cultivo dessas virtudes plantadas por Deus? Quais são os modos como devemos regá-las ou cultivá-las?

Teresa apresenta quatro graus de oração, e fala deles como modos de rezar e cultivar as virtudes plantadas na terra fértil da alma. Os quatro modos de oração são apresentados à luz das quatro maneiras de regar um jardim; diz Santa Teresa:

Paréceme a mi que se puede regar de quatro maneras: u con sacar el agua de un pozo, que es a nuestro gran travajo; u con noria y arcaduces que se saca con un torno - yo lo he sacado algunas veces -: es a menos travajo que estotro, y sácase más agua; $u$ de un río u arroyo: esto se riega muy mijor, que queda más harta la tierra de agua y no se ha menester regar tan a menudo, y es amenos travajo mucho del hortolano; u con llover mucho, que lo riega el señor sin travajo ninguno nuestro, y es muy sin comparación mijor que todo lo que queda dicho. $(V 11,7)$ 
Assim, "dos que começam a ter oração", segundo a moda da oração vocal e mental, Santa Teresa diz que são como "los que sacan el agua del pozo, que es muy a su travajo, como tengo dicho, que han de cansarse em recoger los sentidos" $(V 11,9)$. O recolhimento dos sentidos é aqui a grande tarefa da alma, o trabalho daquele que começa a ter oração vocal e mental, uma vez que é preciso que estas andem juntas porque não é possível que se constitua bem a oração vocal sem consideração do que se reza. Como nossos sentidos "estão acostumados a andar derramados, trata-se então de muito trabalho" ( $V$ 11,9), diz a santa. Por isso, diz Santa Teresa: "Han menester irse acostumbrando a nos se les dar nada de ver ni oír" ( $V$ 11,9), isto é, acostumar-se ao silêncio e à solidão, podem favorecer o recolhimento dos sentidos, e preparar a mente para o trabalho das potências da alma (memória, inteligência e vontade), especialmente do intelecto, que há de concentrar-se no que se diz na oração vocal. Também a memória e a vontade exercerão aqui um papel fundamental. São as potências da alma que, calados os sentidos, serão as responsáveis pelo trabalho de tirar a água do poço através da oração vocal e mental.

Para Santa Teresa, a água do poço, bem como do rio, do riacho ou da chuva, é aqui compreendida como símbolo da emoção e do sentimento que a oração desperta; diz Santa Teresa: "Llamo 'água' aqui las lágrimas y, aunque no las hayas, la ternura y sentimiento interior de devoción." ( $V 11,9)$. Teresa apresenta quatro graus de oração, e fala deles como modos de regar e cultivar as virtudes plantadas na terra fértil da alma (cf. $V$ 11,7). Em seguida ela passa a caracterizar em que consistem esses quatro graus ou modos de oração. O primeiro deles é a oração mental (cf. $V$ 11,9-13); o segundo chama-se oração de quietude (cf. $V$ 14,1ss.); o terceiro é denominado sono das faculdades (cf. V 16,1ss.); e o quarto é chamado de oração de união (cf. $V$ 18,2).

Para tratar deste primeiro modo de oração vocal e mental no Caminho de Perfeição, escrito para suas irmãs de claustro, que lhe pediram que "lhes dissesse o princípio de oração" ( $C P$, Codice El Escorial, 24, 1), Teresa novamente a compara com o movimento daqueles "que quieren bever de este agua de vida y quieren caminar hasta llegar a la mesma fuente" (CP, Codice El Escorial, 35, 2; Codice de Valladollid, 21,2). E "como han de comenzar"? (CP, Codice El Escorial, 35, 2; Codice de Valladollid, $21,2)$. Responde a Santa: con "una grande y mui determinada determinaciónde no parar hasta llegar a ella" (CP, Codice El Escorial, 35, 2; Codice de Valladollid, 21,2); e para isso, diz Teresa, "basta el Paternóster y Avemaría". E acrescenta: "Esto ansí lo digo yo, hermanas; iy cómo si basta! Siempre es gran bien fundar vuestra oración sobre oraciones dichas de tal boca como la de el Señor" ( $C P$, Codice de Valladollid, 21,2; cf. Codice El Escorial, 35, 2). Recolhidos os sentidos, resta à alma, na oração vocal e mental concentrar-se nas palavras do Mestre Jesus. Aqui deve-se justamente chamar à atenção para o fato de que a expressão orante transmitida torna-se o solo no interior do qual o cultivo da experiência mística se constitui. Tal expressão orante tomada aqui por Santa Teresa como meio, porta de entrada e caminho é o que Heidegger chegou a pensar como um "fenômeno do processo de constituição da presença de Deus"; para ele, como já vimos, tratava-se mesmo de um fenômeno "originário", passível de ser pensado e considerado em orientação fenomenológica em função do sentido que tal experiência exprime. Os "passos da oração", a saber, a "concentração, meditação, oração de quietude" (Heidegger, 1995, p. 336) tornam-se, por assim dizer, os aspectos da experiência constituinte da expressão orante pelo qual o fenômeno da presença de Deus constituído nesta experiência poderia ser pensado.

Desse modo, a consideração de Santa Teresa, a respeito da expressão orante estabelecida nas conhecidas orações do Pai nosso e da Ave Maria como meio, porta de acesso e caminho para a oração vocal a ser meditada, deve-nos indicar o horizonte de 
sentido ao qual temos que ter atenção, se pretendemos entender fenomenologicamente em que sentido o fenômeno da presença de Deus se constitui na experiência mística. Santa Teresa procura devolver-nos como elemento básico fundamental, para a oração dos que principiam, a oração do Pai nosso, que, de acordo com o eminente teólogo luterano Joachim Jeremias, consiste em ipsissima vox de Jesus. De acordo com este teólogo: "Jesus ousou empregar [a forma aramaica] 'Abba [Pai] como invocação de Deus. Esse 'Abba é ipssissima vox de Jesus" (JEREMIAS, 2004, p. 118, n. 100). Esta expressão de Jesus foi legada ao ocidente cristão inicialmente pelas cartas de Paulo aos Romanos e aos Gálatas. Na primeira carta, diz Paulo:

Todos os que são guiados pelo Espírito de Deus são filhos de Deus. E vocês não receberam um espírito de escravos para recair no medo, mas receberam um espírito de filhos adotivos, por meio do qual clamamos: Abba! Pai! [ả $\beta \beta \alpha$ ó $\pi \alpha \tau \eta ́ \rho]$. O próprio Espírito assegura ao nosso espírito que somos filhos de Deus

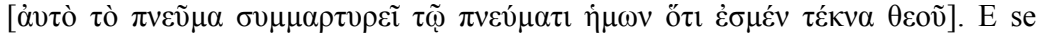
somos filhos somos também herdeiros: herdeiros de Deus, herdeiros junto com Cristo. (Rm 8, 14-17)

Este texto que exprime a compreensão de Paulo dessa expressão orante dá testemunho de que a assunção da ipssissima vox com que Jesus se dirigia a Deus dá-se como uma comunicação do Espírito Divino, que se exprimiu pela boca de Jesus, ao nosso espírito, que, agora, com ele, na oração vocal, clama: Abba, ó Pai!. Essa comunicação amorosa, a fé-amor da qual falara Heidegger - quando se perguntara se porventura o fenômeno da presença de Deus se constituiria já na oração ou se já se encontrava de algum modo "previamente dado na fé ('amor')" (HEIDEGGER, 1995a, p. 307) - não se constitui por causa de uma lei que se tem que cumprir. O Amor que se revela na História e no Tempo, na Plenitude do Tempo, é comunicado e repetido na intimidade do amor de quem pronuncia vocalmente as palavras (expressões) de Jesus na oração e a elas se atém. Tal experiência de constitui numa relação historial, de tal modo que, como diz Heidegger, na sua conferência Der Begriff der Zeit (O Conceito de Tempo): "a fé cristã deve ter acesso a algo que aconteceu no tempo - como se ouve, de um tempo do qual se diz: ele foi o tempo 'em que o tempo foi plenificado....." (HEIDEGGER, 1995b, p. 6).

Heidegger se refere ao texto da carta de São Paulo aos Gálatas, a qual repete e, em certo sentido, aprofunda o que fora transmitido na carta aos Romanos citada acima. Pois nela, diz Paulo:

Quando chegou a plenitude do tempo, Deus enviou o seu Filho. Ele nasceu de uma mulher, submetido à Lei, para resgatar aqueles que estavam submetidos à Lei, a fim de que fôssemos adotados como filhos. A prova de que vocês são filhos é o fato de que Deus enviou aos nossos corações o Espírito do seu Filho que

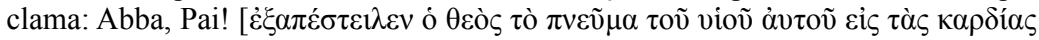
$\dot{\eta} \mu \tilde{\omega} v \kappa \rho \tilde{\alpha} \zeta o v \alpha \beta \beta \alpha$ ó $\pi \alpha \tau \eta ́ \rho]$. (Gl 4, 4-6)

Por meio desta comunicação, que assume um caráter de transcendência na imanência, pois se trata de uma compreensão que entende Deus como fonte de tal comunicação, que enviou aos nossos corações o Espírito de seu Filho que clama Abba, Pai, "solo conocemos", como diz o teólogo católico Gustavo Gutiérrez, "al hombre efetivamente llamado a la comunión gratuita com Dios" (GUTIÉRREZ, 1977, p. 200)15. É este chamado à comunhão com Deus que a assunção da oração do Pai nosso pode promover, na medida em que é pronunciada por aqueles que começam a ter oração, como diz Santa Teresa, e seguem me-ditando estas palavras comunicadas pelo "Sopro" Santo da voz do Galileu de Nazaré. Trata-se de um processo de santificação historial, 
que se constitui pela voz, pelo ouvido e pela "mente", recolhidos nesta ipssissima vox de Jesus. Esta é, por assim dizer, a qualidade da relação historial da existência temporânea estabelecida por meio da oração transmitida: a santificação por meio da comunhão expressiva que se dá na meditação concentrada da oração, a qual é considerada na fé como sendo transmitida a partir de uma fonte histórica de manifestação transcendente (divina) na imanência do tempo (história) ${ }^{16}$. Tal compreensão de fé pode ser compreendida como uma região doadora de sentido histórico prévio (ou horizonte doador de sentido histórico prévio) em que se constitui um encontro essencial; algo a que Heidegger se refere justamente com os termos "historische Vorgegebenheit" e "Wesensfindung" (HEIDEGGER, 1995a, p. 311).

De acordo com Santa Teresa, é justamente pela transmissão e emissão da palavra e devoção pela oração que foi comunicada pela boca de Jesus que Santa Teresa entende como ela deve servir de fundamento e meio para a oração vocal e mental neste princípio do cultivo da alma.

No Livro da Vida Santa Teresa esclarece que na oração mental o que está em jogo é o trabalho do intelecto, que busca o cultivo dos bons pensamentos: “... esse trabalho com o intelecto", diz Santa Teresa, "é tirar água do poço" $(L V 11,10)$. O poço deve ser compreendido como a memória. O trabalho consiste em pensar na vida de Cristo e na sua própria vida. Duas advertências se impõem como importantes nesse contexto: "Não se incomode com os maus pensamentos" ( $L V 11,10)$; “... o amor de Deus não está em ter lágrimas nem em ter esses gostos e essa ternura, que, em geral, desejamos e com os quais nos consolamos, mas em servir com justiça, força de ânimo e humildade" $(L V 11,13)$

Se no Livro da Vida Santa Teresa se atém às disposições e atividades fundamentais da oração mental, no Caminho de Perfeição ela se atém ao seu conteúdo fundamental, comunicado através da oração vocal. O Pai nosso, compreendido como paradigma da oração vocal cristã se estabelece como uma evocação, que, ao mesmo tempo em que assume a ipssisima vox e ipssissima verba de Jesus, convoca a vida religiosa a dirigir seu olhar para o interior da alma (da consciência), e para aquele a quem a oração se dirige, provocando na vida do religioso (na alma, na consciência) o que Heidegger chama de uma "motivação originária da relativa vivência" (HEIDEGGER, 1995a, p. 311). Trata-se de uma vocação (motivação, impulso motivado, motivo místico, cf. HEIDEGGER, 1995, p. 309-311) para retirar-se de seu movimento habitual cotidiano de atenção e resposta aos apelos das demandas de sua atividade no mundo, com suas ocupações e preocupações emergentes. $\mathrm{O}$ "olhar espiritual" da alma (a direção do olhar para o interior da própria vida), que, na sua vida cotidiana, se mantém por ele e através dele aberto à sua vida sensitiva, lançando-se no corpo e através do corpo para fora de si, é, repentinamente convocado para dentro, voltando-se para si e para o que reside no interior da alma. As palavras do Pai nosso colocam para a existência que crê, para a pessoa em atitude mística, uma motivação originária: exigem do olhar espiritual da alma que se mantenha com determinação atento ao Mestre pela boca de quem tais palavras são comunicadas, e, numa me-ditação de tais palavras, se volte para aquele a quem se dirige e que habita em seu interior (isto é, "no céu de sua alma" ${ }^{17}$ ). A terra se faz aqui símbolo das demandas e ocupações do mundo, ao qual toda a atividade anímico corpórea se mantém habitualmente vinculada com todos os seus sentidos e capacidades ou potências. O céu é o interior da alma, cuja entrada requer a oração vocal e mental, que envolve o recolhimento dos sentidos e das potências da alma. A santificação da atividade habitual da terra depende da unidade da alma com quem está no céu, em seu centro mais profundo, na interioridade da alma.

A solidão se torna aqui o primeiro momento essencial, como já nos indicara 
Heidegger no esboço de sua preleção (cf.p.). "Pois", diz Santa Teresa, "já sabéis que enseña este maestro celestial sea a solas; que ansí lo hacía el siempre que orava, no por su necesidad, sino por nuestro ensiñamento" (CP, cod. El Escorial, cap. 40,3; cod. de Valladolid, 24,4). Dese modo "hemos de procurar estas a solas, y aun plega a Dios entendamos com quién estamos y lo que nos responde el Señor a nuestras peticiones" (CP, cod. de El Escorial, 40,4; cod. de Valladolid, 24,4). Assim, Santa Teresa recomenda que a oração vocal do Pai nosso seja acompanhada do recolhimento dos sentidos e considerações do pensamento para com aquele que ensinou o Pai nosso e para com aquele a quem se dirige a oração, ficando a alma, ademais, atenta a Sua resposta.

\section{O Ponto de Chegada à luz da alegoria do Castelo Interior (CI)}

A lida (uti) cotidiana como fruição (frui) e trato e a visão intelectual tornam-se o ponto de chegada da oração tal como Teresa a descreve. Daí podemos falar, a partir do próprio Heidegger, da experiência agostiniana própria da mística medieval presente no pensamento de Teresa. Há uma dupla orientação: para o interior como visão intelectual; e para o exterior como lida e trato cotidianos com os outros, experimentado sob a forma do serviço amoroso. Na conquista dessas duas orientações consiste o ponto de chegada do caminho espiritual da mística teresiana.

De acordo com Heidegger, no apêndice do curso sobre Agostinho, à luz de sua intrpretação da vida cristã, tal como ela emerge a partir de Agostinho, "uma característica fundamental da vida é o curare (o ser solícito)" (GA 60, p. 271). A solicitude se constitui aqui sob duas perspectivas: a do modo como se lida (umgehen) com as coisas e trata com os outros (caracterizado por Agostinho, segundo Heidegger, pelo termo uti); a perspectiva da fruição (geniessen), caracterizada por Heidegger do seguinte modo: "um sentido fundamental determinado esteticamente" (GA 60, p. 271). Trata-se fundamentalmente da fruição da presença divina: "Somente a trinitas tem de estar na fruição, a qual é o Bem mais alto e imutável" (GA 60, p. 271). Desse modo, “o sentido fundamental estético da fruição" é aquilo que Agostinho, nas confissões, denominou de "Beleza tão antiga e tão nova", sobre a qual também se fala segundo Heidegger na Epístola LV: "fruendum est trinitate, rei intelligibilis pulchritudo (=

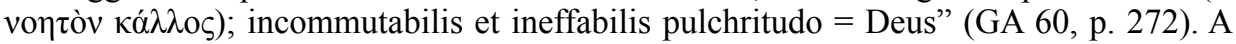
fruição do Deus trino como "beleza inteligível e inefável” é o que caracteriza a vivência mística e seu correlato. De acordo com Heidegger:

A 'fruitio dei' é um conceito decisivo na Teologia medieval; ele é o motivo principal, que conduziu à formação da Mística medieval.

A 'fruitio' [concebida] por Agostinho não é, porém, a especificamente plotiniana, que culmina na intuição [Anschauung], mas está enraizada na concepção propriamente cristã da vida fática. (HEIDEGGER, GA 60, p. 272, grifo do autor)

Podemos ver que, na perspectiva de Teresa de Ávila, a experiência de oração conduz justamente a esses dois momentos, como destinos fundamentais da experiência mística: a fruição de Deus e a solicitude em vista de uma vida em favor dos desígnios divinos. Ela a denomina de união da alma com Deus, no interior de si mesma. De acordo com Teresa, ela ocorre no centro mais profundo da alma, ou melhor, como diz Santa Teresa, no espírito (cf. CI 7M 2,14). Ela considera que há diferença entre a alma e o espírito da alma (cf. CI 7M 1,12). Quando Deus realiza na alma esta graça, Ele 
pretende mais do que faz pela primeira vez, quando se revela por meio de uma visão imaginária. Este matrimônio espiritual, entendido como "secreta união", "se passa... no centro muito interior da alma, que deve ser onde está mesmo Deus". Aí "o Senhor aparece neste centro da alma sem visão imaginária, mas intelectual" (CI 7M 2,3, grifo meu).

Aqui se deve chamar a atenção para esse caráter intelectual (noético) da visio dei como destino da experiência mística. Teresa a explicita do seguinte modo: "metida naquela [sétima] morada por visão intelectual por certa maneira de representação da verdade, mostra-se-lhe a Santíssima Trindade, todas três Pessoas, com uma inflamação que primeiro vem a seu espírito à maneira de um nuvem de grandíssima claridade", e, "por uma notícia admirável que se dá à alma", esta "entende com grandíssima verdade ser todas três Pessoas", que se lhe mostram como "Pessoas distintas", "uma substância e um poder, e um saber e um só Deus" (CI 7M 1,7). Aqui, como já lembrava Heidegger em sua leitura de Agostinho, a trinitas se constitui como correlato da experiência de fruição mística, que não se esgota, porém, apenas em uma quietude passiva.

Teresa de Ávila há de considerar justamente que de nada poderá valer a oração se não for acompanhada de uma solicitude que lhe corresponde. Diz Teresa:

Para esto es la oración, hijas mías; de esto sirve este matrimónio espiritual, de que nazcan siempre obras, obras. Esta es la verdadeira muestra de ser cosa y merced de Dios, como ya os he dicho; porque poco me aprovecha estarme muy recogida a solas, haciendo actos com nuestro Señor, propuniendo y prometiendo de hacer maravillas por su servicio, si em saliendo de allí, que se ofrece la ocasión, lo hago todo al revés. (CI 7M 6-7)

Esta atitude habitual de serviço e disponibilidade solícita e amorosa corresponde à fruição de Deus constituída na experiência mística. Ela se enraíza na própria experiência fática, tal como é propriamente concebida pela vida cristã. De acordo com Heidegger, torna-se também digno de questão "se precisamente com a mera visão de Deus [Schauen Gottes], como o lado positivo do desprendimento, atinge-se o [fenômeno] genuíno e se a forma da união (Form der Einigung] não será outra. 'Amor'." (HEIDEGGER, 1995a, p. 308; cf. tb. HEIDEGGER, 2010, p. 294).

\section{CONSIDERAÇões Finais}

Vê-se por essa exposição, que a experiência mística possui um sentido fundamental, que se faz possível descrever fenomenologicamente à luz de um paradigma histórico dessa vivência, tal como foi a experiência relatada por Teresa de Ávia em seus escritos. A consideração do que ela descreve como experiência de oração se torna a base para a compreensão do modo como se constitui a presença de Deus como presença amorosa na experiência mística, e ajuda-nos a entender porque Heidegger considerava que Teresa vê fenomenologicamente, ainda que não eideticamente, mas na perspectiva de uma descrição fática da atitude orante habitual da experiência cristã. A perspectiva poética com que tal descrição é feita e a diferença entre ela (como caracterização imaginária) e o significado da visão intelectual na imanência da experiência, exige, contudo, ainda, um maior aprofundamento, no sentido de que se torne claro o caráter transcendente ou sobrenatural com que os místicos caracterizaram uma tal visão, e a diferença desta em relação à intelecção natural.

\section{REFERENCIAS}


GUTIÉRREZ, G. Teología de la Liberación: Perspectivas. 8 ed. Salamanca: Sígueme, 1977.

HEIDEGGER, M. Phänomenologie des religiösen Lebens. Gesamtausgabe 60 (GA 60). Frankfurt am Main: Vittorio Klostermann, 1995a.

HEIDEGGER, M. Fenomenologia da Vida Religiosa, trad. Enio Paulo Giachini, Jairo Ferrandin e Renato Kirchner. Petrópolis: Vozes/ Bragança Paulista: Editora Universitária São Francisco, 2010.

HEIDEGGER, M. Der Begriff der Zeit. 2 ed. Tübingen: Max Niemeyer, 1995 b.

ISABEL DA TRINDADE, Beata. Obras Completas, trad. Carlos H. do C. Silva. Marco de Canaveses, Portugal: Edições Carmelo, 2008.

JEREMIAS, J. Teologia do Novo Testamento, trad. João Rezende Costa. São Paulo: Teológica/ Paulus, 2004.

STEIN, E. Selbstbildnis in Briefen III. Briefe an Roman Ingarden. Edith Stein Gesamtausgabe 4 (ESGA 4). 2 ed. Freiburg in Breisgau/ Basel/ Wien: Herder, 2005.

STEIN, E. A Ciência da Cruz: Estudo sobre São João da Cruz, trad. D. Beda Kruze. São Paulo: Loyola, 2016

TERESA DE JESUS, Santa. Obras Completas. 8 ed. Madrid: Biblioteca de Autores Cristianos, 1986.

\section{NoTAS}

1 Também em carta a Roman Ingarden, escrita quando ela se encontrava em Breslau e datada de 30 de agosto de 1921, Edith Stein declara: "Eu estou agora em casa às voltas com um tratado em torno da filosofia da religião" (ESGA 4, p. 140), que, segundo ela, ainda não sabia o que se tornaria. De acordo com os editores de suas obras completas, trata-se de um manuscrito que só foi publicado postumamente em 1962 na ESW VI, sob o título de Natur, Freiheit und Gnade (Natureza, Liberdade e Graça; cf. ESGA 4, p. 140-141, n. 6; ESW VI; ESGA 9). Heidegger desenvolveu ainda duas preleções em Freiburg em torno desse tema: uma no semestre de inverno de 1920/21, intitulada Einleitung in die Phänomenologie der Religion [Introdução à Fenomenologia da Religião]; e outra no semestre de verão de 1921, intitulada Augustinus und der Neuplatonismus [Agostinho e o Neoplatonismo] (cf. GA 60, p. 1-246).

2 A motivação original (Urmotivation, cf. GA 60, p. 336), a compreensão temporânea, que possui um "determinado aspecto" negativo em que o momento constituinte da relação com o mundo é caracterizado negativamente como repulsiva, e, positivamente, como "visão de Deus" (cf. GA 60, p. 308).

3 Vê-se aqui já um movimento de orientação para uma transformação da fenomenologia em compreensão hermenêutica da facticidade, que só chegará a ser elaborada de maneira mais explícita com o curso "Ontologia: Hermenêutica da Facticidade" (1923), chegando a alcançar em "Ser e Tempo" (1927) o método mesmo de sua Filosofia Existencial, na medida em que a define como uma "ontologia fenomenológica universal, que parte da hermenêutica do ser-aí e, enquanto analítica da existência, amarra o fio condutor de todo questionamento no lugar de onde ele brota e para onde retorna".

4 É preciso considerar, contudo, que vamos nos ater à dinâmica própria de uma investigação no âmbito da fenomenologia como filosofia da consciência, ou seja, sem considerar a virada heideggeriana para uma filosofia da existência propriamente dita, que já se deixa mostrar nesses cursos iniciais de Heidegger em Freiburg, ainda bastante ligados à fenomenologia husserliana, mas já apontando para uma transformação do método em uma fenomenologia hermenêutica de caráter existencial. Desse modo, se por um lado evitamos cair no âmbito da facticidade da existência pura e simples, por outro lado evitaremos também a suposição fílosófico metafísica da sobrenaturalidade, própria da investigação de caráter metafísico steiniana. Considero que, desse modo, mantemo-nos fiéis ao projeto próprio da filosofia fenomenológica tal como Husserl a estabeleceu, sem aportar os dados da facticidade, que ele considerava transcendentes e dignos de serem postos entre parênteses, e sem deixar-se conduzir por uma investigação de caráter metafísico, que 
exige supor Deus e sua ação como instâncias de caráter sobrenatural, que, como dados transcendentes, Husserl também colocaria entre parênteses e fora de circuito.

5 Esta é a expressão utilizada por Edith Stein em Ser finito e eterno; ensaio de uma ascensão ao sentido do ser.

6 Esta é a expressão utilizada por Santa Teresa em seu Castelo Interior.

$7 \mathrm{Ou}$ "aquele" (isto é, Deus), ou mesmo talvez para a graça ou para o mistério.

8 Sobre isso, Edith Stein fala belamente a respeito da expressão poética da experiência mística realizada por São João da Cruz: "Seus escritos místicos são [...] interpretações posteriores de suas concepções poéticas. [...] Na impressionabilidade vigorosa e genuína, o artista, a criança e o santo muito se assemelham. [...] o artista dá forma ao que o toca intimamente, transformando-o em imagens interiores que, por sua vez, o impulsionam a exteriorizá-las concretamente. Essas imagens não se restringem somente ao campo visual ou às artes plásticas; entende-se por "imagem" qualquer expressão artística - incluindo a poesia e a música - consistente na representação de alguma coisa na qual o representado é concretizado e acabado; em outros termos, a representação de um microcosmo. Toda obra de arte, independentemente da intenção do artista, é, ao mesmo tempo, um símbolo. É indiferente que o artista, em sua expressão, seja naturalista ou simbolista. Há um símbolo quando algo da plenitude do sentido das coisas penetra a mente humana e é captado e apresentado de tal maneira que a plenitude do sentido - inexaurível para o conhecimento humano - seja misteriosamente insinuada. Desse modo, toda arte verdadeira é uma espécie de revelação, e a produção artística, um mistério sagrado." (Edith STEIN, $A$ Ciência da Cruz: Estudo sobre São João da Cruz, trad. D. Beda Kruze. São Paulo: Loyola, 2016, p. 13-14).

9 Acrescenta Heidegger na citação (cf. GA 60, p. 337).

10 Não devemos já de antemão pressupor que a meditação seja um mero exercício, sendo mais propriamente passível de ser denominada uma atividade da alma, mas que não pode ser desvinculada de algo como a experiência de um mistério, o que constitui o caráter místico de tal atividade. O místico se move no horizonte da fé e do que se constitui nesse horizonte, desde a palavra legada até à experiência de mundo e das coisas do mundo e seu modo de significação. Este horizonte deve ser levado em conta na compreensão da meditação.

11 A expressão como palavra legada a ser meditada e levada em consideração.

12 No original: "Porque la [oración] que no advierte con quién habla y lo que pide y quién es quien pide y a quién, no la llamo yo oración, aunque mucho menee los labios" (CI 1M $1,7)$

13 Há variações de um códice para outro, mas que não interferem no sentido próprio do trecho citado.

14 Desde o ponto de vista da fenomenologia husserlliana, Deus, como fonte transcendente da comunicação, é colocado entre parênteses. Devemos interrogar, portanto a respeito do sentido do reconhecimento do dado transcendente na imanência da consciência e em que ele se funda. É certamente um dado da fé, experimentado na imanência da consciência como reconhecimento da transcendência de Deus, que se compreende manifestando-se no instante da comunicação mística, sem que nela se esgote. Deus é compreendido por Teresa como aquele que se antecipa à experiência do místico, do que começa a ter oração.

15 De acordo com Joachim Jeremias, esse testemunho de São Paulo na Carta aos Romanos 8,15 e aos Gálatas 4, 6 manifesta que esse 'Abba "soava como invocação na oração" das comunidades cristãs, tanto aquelas fundadas por ele, como outras (cf. JEREMIAS, 2004, p. 117). Segundo ele: "O caráter incomum dessa invocação de Deus [na tradição orante hebraica] comprova que ela é um eco da oração de Jesus" (JEREMIAS, 2004, p. 117). De acordo com suas pesquisas, "em toda a vasta literatura do judaísmo antigo não se encontra em parte alguma um testemunho para a invocação de Deus com 'Abba, nem em orações litúrgicas nem em orações privadas" (JEREMIAS, 2004, p. 117). Isto ocorre de tal modo que, segundo ele: "Temos, pois, todos os motivos para contar com o fato de que

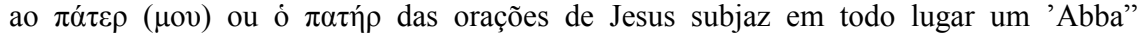
(JEREMIAS, 2004, p. 117). Segundo Joachim Jeremias: "A inovação mais importante no 
uso da linguagem por parte de Jesus é o emprego da palavra corriqueira 'Abba como interpelação de Deus" (JEREMIAS, 2004, p. 79). Ainda de acordo com ele: "A total novidade e singularidade da interpretação de Deus com 'Abba nas orações de Jesus evidencia que ela expressa o cerne da relação de Jesus com Deus. Ele falou com Deus como uma criança com seu pai: cheio de confiança e sentindo-se acolhido e, ao mesmo tempo, respeitoso e pronto à obediência" (JEREMIAS, 2004, p. 121).

16 Para a consciência religiosa na $f e ́$, a fonte originária da revelação divina é compreendida "dogmaticamente" como transcendente. É assim que, como cita o próprio Heidegger, Wilhelm Windelband, em seu texto Das Heilige. Skizze zur Religionsphilosophie (O santo. Esboço para uma filosofia da religião), compreende o caráter da santidade da experiência religiosa: "Das Heilige ist also das Normalbewusstsein des Wahren, Guten und Schöhnen, erlebt als transzendente Wirklichkeit" (WINDELBAND apud HEIDEGGGER, 1995a, p. 315), isto é: "O santo é então a consciência normal do verdadeiro, do bom e do belo, vivenciada como realidade transcendente"; mas, para a consciência fenomenológica, o fenômeno da presença de Deus só pode ser compreendido ou perquirido na experiência da vivência concreta da consciência mística ou da existência histórica religiosa, como dado imanente. Por isso, Heidegger procurava perquirir em sua análise da experiência religiosa "as conexões imanentes" constituídas nessa experiência.

17 Essa é uma expressão utilizada por outra mística carmelita, a Beata Elisabeth da Trindade. Cf. Isabel da Trindade, Obras Completas, trad. Carlos H. do C. Silva. Marco de Canaveses, Portugal: Edições Carmelo, 2008, p. 127. Ela remete contudo à própria Santa Teresa de Ávila que, no seu Caminho de Perfeição considera a alma como um pequeno céu, ao falar dele como "este cielo pequeño de nuestra alma" [CP, Códice de Valladolid, 28,5(2)].O Reino do Céu da Comunidade Cristã Primitiva, tal como se deixa exprimir por meio do Evangelho segundo Mateus, ou Reino de Deus, como se deixa exprimir nos outros Evangelhos, tornara-se pelo menos já desde o Evangelho de Lucas um reino que se

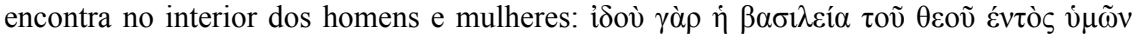
$\dot{\varepsilon} \sigma \tau \imath v$. (Lc 17,21b). Tal expressão de Jesus foi vertido para o latim na Vulgata do

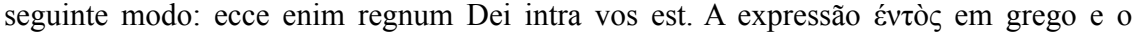
termo latino intra logo puderam apontar para o cristianismo primitivo a ideia de uma presença do Reino do Céu ou do Reino de Deus na interioridade da alma humana. Seguindo a tradição agostiniana é assim que Santa Teresa interpreta no Caminho de Perfeição a evocação do Reino do Céu na oração do Pai nosso, dando a compreender todo o seu caminho místico como um percurso para dentro do interior da alma, este pequeno céu onde Deus habita. Se Deus está no Céu e a alma é um pequeno Céu onde Deus está, compete à alma dirigir-se para este interior. Por isso, Santa Teresa admoesta, dizendo: "Poned los ojos en vos e miraos interiormente; allaréis vuestro Esposo, que no os faltará" [CP, Codice de El Escorial, 48,1; var. Codice de Valladolid, 29, 1(6)]. Esinar a orar é, assim, ensinar a olhar, e olhar para dentro de si mesmo, Céu da alma onde Deus se encontra: "recoger [...] la vista para mirar dentro de si a este Señor" (CP Codice de Valladolid 26, 8). A própria Teresa nos remete a Santo Agostinho, quando diz: "Ya sabeis [...] que adonde está Dios, es el cielo. [...] Pues mirad que dice san Agustín que le buscava en muchas partes y que le vino a hallar dentro de sí mismo." ( $C P$ Codice de Valladolid 28,2 ). 